\title{
Prevalence of Hepatitis B and C Viral Infection Among Pregnant Women in Peshawar, Pakistan
}

\author{
Irshad Ahmad, ${ }^{1, *}$ \\ ${ }^{1}$ Assistant Professor, Department of Life Sciences, King Fahd University of Petroleum and Minerals, Dhahran, Saudi Arabia \\ "Corresponding author: Irshad Ahmad, Assistant Professor, Department of Life Sciences, King Fahd University of Petroleum and Minerals, Dhahran, Saudi Arabia. Tel: \\ +96-638607032, Fax: +96638604277, E-mail: irshad@kfupm.edu.sa
}

Received 2016 January 16; Revised 2016 May 03; Accepted 2016 May 13.

\begin{abstract}
Background: Viral hepatitis during pregnancy is associated with a high risk of maternal complications. The virus has a high risk of vertical transmission and it has been reported as the leading cause of maternal death.

Objectives: To study the prevalence of hepatitis B (HBV) and hepatitis C (HCV) viral infections among pregnant women in the Peshawar district of Pakistan.

Materials and Methods: The cross-sectional study took place between July 2013 and April 2014. A total of 10,288 samples were collected from pregnant women living in different areas of the Peshawar district. The samples were centrifuged at a high speed in order to obtain a clear supernatant serum. All samples were screened for HBV and HCV using the immunochromatographic technique. Results: The overall prevalence of $\mathrm{HBV}$ was found to be $1.16 \%$, although it varied throughout the study period. The highest prevalence of HBV (1.69\%) was observed during January 2014. The overall prevalence of HCV infection among the pregnant women was observed to be $1.42 \%$. The highest prevalence of HCV infection (2.22\%) was found during March 2014.

Conclusions: The overall prevalence of HBV and HCV was 1.16\% and 1.42\%, respectively. The incidence of HCV infection among the pregnant women was higher than that of HBV infection.
\end{abstract}

Keywords: HBV, HCV, ICT, Prevalence

\section{Background}

Viral hepatitis is a major global health concern, affecting 2 - 15 million people each year. The hepatitis B virus (HBV) and the hepatitis $\mathrm{C}$ virus (HCV) have infected approximately 400 and 200 million people, respectively, worldwide (1). In Pakistan, the situation is worse than in the developed countries of the world. Among the hepatitis viruses, HBV and HCV are the most prevalent in this region and hence they require extensive research. Recently, the Pakistan medical research council (PMRC) conducted a national survey on the prevalence of hepatitis B and C among the general population of Pakistan. The preliminary reports reveal that the prevalence of HBsAg and anti-HCV infection is $2.5 \%$ and $4.9 \%$, respectively. The overall level of positivity for both viruses is $7.4 \%$, indicating that there are 12 million infected people in Pakistan (2).

The sexual transmission of hepatitis $\mathrm{B}$ and $\mathrm{C}$ has also been described, and the transmission of the hepatitis $\mathrm{B}$ virus has been found to be the more prevalent in this regard (3). Many countries have already adopted proper blood screening procedures that have minimized the risk of such viruses being transmitted through blood transfusion. HBV positive mothers with an HBsAg positive status can vertically transmit the infection to their infants. This risk of transmission may increase if the mother develops the HBV infection during the third trimester of pregnancy. Recent reports have shown that the provision of antiviral therapy in the third trimester is a safe and effective means of reducing the perinatal transmission of HBV (4-6). The risk of HCV transmission from viremic mothers to their infants is 3.2\%, although it may increase to $7.9 \%$ if the mother is co-infected with $\operatorname{HIV}(7,8)$. Moreover, co-infection with HBV and HCV can lead to chronic hepatitis, cirrhosis, and hepatocellular carcinoma (9-12).

Recently, the health status of mothers and children in relation to hepatitis $C$ infection has become a matter of concern worldwide. The availability of effective screening methods for HCV has decreased the incidence of new cases of transfusion-associated hepatitis $C$ infection in children. However, childhood acquisition of HCV infection through maternal-infant transmission has become one of the most common modes of transmission. HCV is also commonly transmitted through the injection of drugs, inadequate sterilization of medical equipment, especially syringes and needles, unscreened blood transfusion, and perinatal transmission (13).

An estimated 40,000 children are born annually to 
HCV-infected women, resulting in up to 4000 new perinatally infected children each year $(14,15)$. Pregnancy does not affect the clinical course of hepatitis C. Different studies have shown an improvement in the biochemical markers of liver damage in HCV positive women during pregnancy. This phenomenon was observed during hemodilution in pregnancy because the transaminase levels returned to pre-pregnancy levels shortly after delivery. However, it is possible that changes in the immune response during pregnancy can play a significant role in the HCV interaction. In contrast to the improved parameters of liver dysfunction, a linear increase in HCV viremia has been reported throughout pregnancy, a fact that may be compatible with impaired immune reactivity $(16,17)$. Additionally, interferon and ribavirin are contraindicated during pregnancy due to their possible teratogenic/abortifacient effects (18).

\section{Objectives}

Routine antenatal HCV screening in order to prevent vertical transmission is an important area of concern globally. HCV infection is a serious public health problem for which reliable screening tests exist. Viral hepatitis during pregnancy is associated with a high risk of maternal complications. It has a high risk of vertical transmission and it is the leading cause of maternal death. With this in mind, the present study focused on the prevalence of hepatitis B and $\mathrm{C}$ infection among pregnant women in the Peshawar district of Pakistan.

\section{Materials and Methods}

\subsection{Study Area}

This cross-sectional study was conducted at the Molvi Jee Hospital, Peshawar, Pakistan from July 2013 to April 2014. It is a tertiary care hospital that provides prenatal care services to pregnant women living in Peshawar. The hospital caters to the needs of those from the lower socioeconomic section of society, although its equipment is state of the art when compared to the rest of the hospitals in the area adjoining Peshawar. Indeed, this hospital is the first choice care facility for most people, especially for the treatment of gynecological cases.

\subsection{Study Population}

In this study, blood samples were collected from pregnant women who were admitted for their perinatal checkups at the hospital. The patients live in different areas of
Peshawar. The history of the studied population (i.e., pregnant women) was recorded on forms approved by the hospital's ethical review committee. Informed consent was obtained from all patients and appropriate confidentiality was maintained throughout the study.

\subsection{Sample Collection}

A total of 10,288 samples were collected from pregnant women who were admitted to the hospital. Approximately $5 \mathrm{cc}$ of blood was collected from each individual in a gel vacutainer. The age group included in this study was 20 - 40 years. The samples were centrifuged at 2000 revolutions per minutes (rpm) for 5 minutes in order to obtain a clear supernatant serum. The sera were then stored at $20^{\circ} \mathrm{C}$ prior to the serologic assay of $\mathrm{HBV}$ and $\mathrm{HCV}$.

\subsection{Serologic Assay}

All the samples were screened for HBV and HCV infection based on the immunochromatographic technique (ICT). Immunochromatography (SD Bioline HbsAg) is a one-step assay designed for the qualitative determination of HbsAg in human serum or plasma. The test cassette contains a membrane strip that is pre-coated with mouse monoclonal anti-HbS capture antibody on the band region. The mouse monoclonal anti-HbS-colloidal gold conjugate and the serum sample move along the membrane chromatographically to the test region $(\mathrm{T})$ and then form a visible line as the antibody-antigen-antibody gold particle complex forms. For the diagnosis of HCV infection, the recombinant proteins (NS3, NS4, and NS5) were used as the captured materials. The SD Bioline HCV test contains a membrane strip that is pre-coated with recombinant $\mathrm{HCV}$ captured antigen on the test band region. The protein Acolloid gold conjugate and the serum sample move along the membrane chromatographically to the test region and then form a visible line as the antigen-antibody protein Agold particle complex forms with a high degree of sensitivity and specificity.

\subsection{Data Analysis}

All data were statistically analyzed using GraphPad Prism 5 (GraphPad Software Inc. San Diego CA, USA). The prevalence estimates of HBV and HCV infection were reported with $95 \%$ confidence intervals.

\section{Results}

A total of 10,288 blood samples were collected from pregnant women and then screened for HBV and HCV infection using the ICT method. HBsAg and anti-HCV positive 


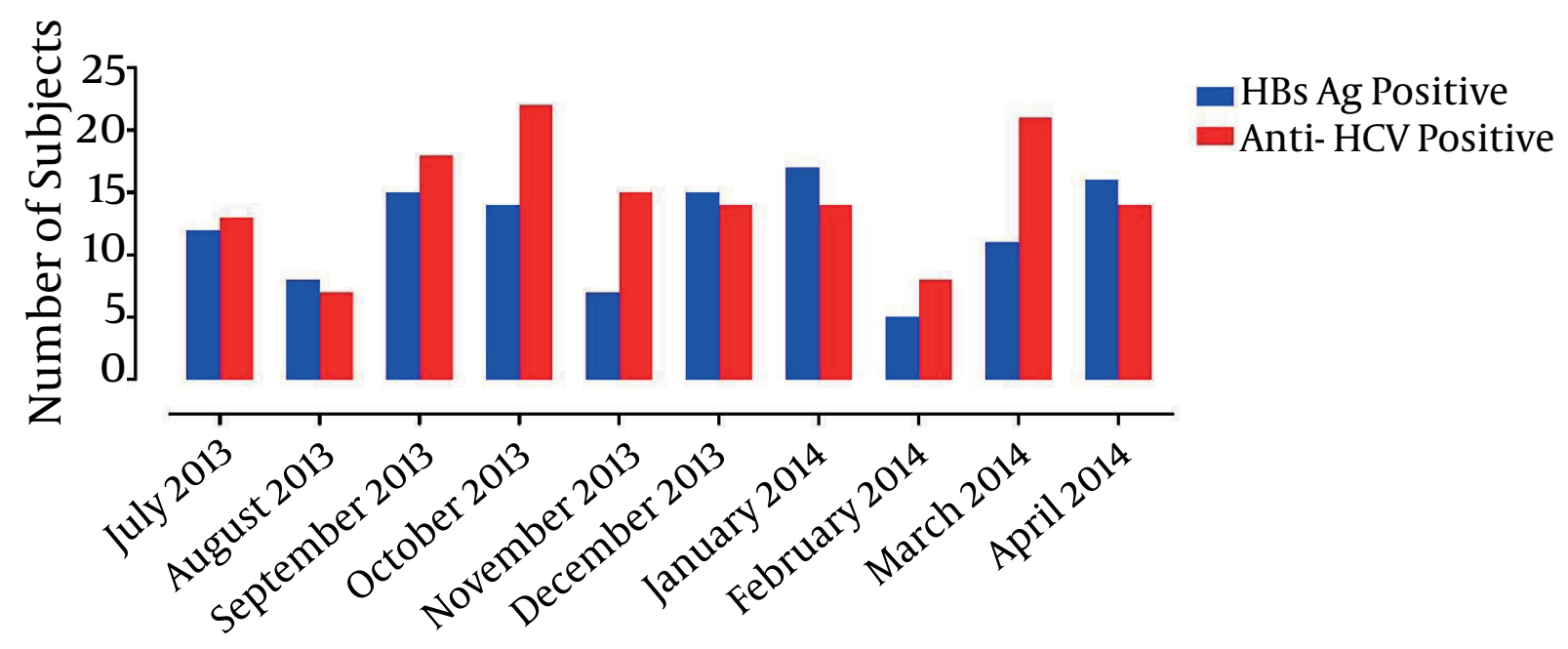

Figure 1. HBsAg and Anti-HCV Positive Cases Among the Pregnant Women From July 2013 to April 2014

cases were reported among the pregnant women from July 2013 to April 2014 (Figure 1).

The overall prevalence of HBV was 1.16\% (0.96 - 1.37), although it varied throughout the year. The monthly prevalence of HBV observed from July 2013 to April 2014 was 1.22\% (0.53-1.91), 0.88\% (0.27-1.49),1.1\% (13.1-16.9),1.29\% (11.9-16.1), $0.66 \%$ (0.17-1.15), $1.39 \%$ (0.69-2.09), $1.69 \%$ (0.89-2.49), $0.60 \%$ (0.07-1.13), 1.16\% (0.48-1.84), and 1.63\% (0.84 - 2.42), respectively. The highest prevalence of $\mathrm{HBV}$ (1.69\%) was observed in January 2014.

The overall prevalence of HCV infection among the pregnant women was $1.42 \%$ (1.24-1.7). The monthly prevalence of HCV from July 2013 to April 2014 was 1.33\% (0.61 2.05), $0.77 \%$ (0.20 - 1.34), 1.33\% (0.72 - 1.94), 2.02\% (1.18 - 2.86), $1.41 \%$ (0.70 - 2.12), $1.30 \%$ (0.62 - 1.98), 1.39\% (0.67 - 2.11), $0.97 \%$ (0.30-1.64), $2.22 \%(1.28-3.16)$, and 1.43\% (0.69- 2.17), respectively. The highest prevalence of $\mathrm{HCV}$ infection (2.22\%) was found in March 2014, while the lowest prevalence (0.77\%) was found in August 2013 (Table 1).

\section{Discussion}

Viral hepatitis is a global issue and in Pakistan the situation is no different from that in the rest of the world. Routine antenatal hepatitis screening to prevent the vertical transmission of hepatitis is a controversial issue and hence it is not universally implemented. Nevertheless, hepatitis is considered to be an important public health problem for which reliable screening tests do exist. Treatment is contra - indicated during pregnancy due to the potential risks of the diagnostic procedure (19).
In the present study, the prevalence of HCV among the pregnant women is reported to be $1.42 \%$, which is lower than the earlier reported prevalence of $9.2 \%$ (20). This difference in findings between the studies could be due to a lack of awareness, low socioeconomic conditions, an unhygienic environment, and differences in the geographical distribution among the countries. However, a prevalence for hepatitis C of $1.03 \%$ was previously found among pregnant women (21), which is in agreement with the findings of the present report.

Hepatitis B infection is also found among pregnant women, particularly in Pakistan. A prevalence of $0.34 \%$ was previously reported in pregnant women (22), while the prevalence in this study was found to be $1.16 \%$. This slight difference in the two prevalence rates is due to the different methods used for the screening of viral infection and a lack of awareness among the people of this country. A previous study conducted in this region reported a $3.98 \%$ prevalence of HBV infection in pregnant women (23), which is slightly higher than that found in the current study. A detailed survey concerning the epidemiology of hepatitis $B$ and $C$ infection in pregnant Yemeni women was previously presented (24). It found $\mathrm{HBV}$ and $\mathrm{HCV}$ prevalence rates of $10.8 \%$ and $8.5 \%$, respectively. This report contradicts the current findings due to a lack of awareness, low education, dental manipulation, a history of miscarriages, and the system for blood transfusion in Yemen. Chronic liver disease is an important health challenge worldwide, and HBV and HCV infections are the main causes of liver insufficiency globally. The risk factors reported in pregnant women were responsible for viral hepatitis B and C infection (25). The study 
Table 1. Frequency of Sera HBsAg and Anti-HCV Positivity Among Pregnant Women During Different Months ${ }^{\mathrm{a}}$

\begin{tabular}{|c|c|c|c|c|c|c|c|}
\hline \multirow[t]{2}{*}{ Month } & \multirow[t]{2}{*}{ Number of Cases } & \multicolumn{2}{|c|}{ HBV Infection } & \multirow[b]{2}{*}{ CI } & \multicolumn{2}{|c|}{ HCV Infection } & \multirow[b]{2}{*}{ CI } \\
\hline & & HBsAg +/- & Percentage & & Anti-HCV +/- & Percentage & \\
\hline July 2013 & 980 & $12 / 968$ & 1.22 & $(0.53-1.91)$ & $13 / 967$ & 1.33 & $(0.61-2.05)$ \\
\hline August 2013 & 913 & $8 / 905$ & 0.88 & $(0.27-1.49)$ & $7 / 906$ & 0.77 & $(0.20-1.34)$ \\
\hline September 2013 & 1352 & $15 / 1337$ & 1.11 & $(13.1-16.9)$ & $18 / 1334$ & 1.33 & $(0.72-1.94)$ \\
\hline October 2013 & 1088 & $14 / 1074$ & 1.29 & $(11.9-16.1)$ & $22 / 1066$ & 2.02 & $(1.18-2.86)$ \\
\hline November 2013 & 1061 & $7 / 1054$ & 0.66 & $(0.17-1.15)$ & $15 / 1046$ & 1.41 & $(0.70-2.12)$ \\
\hline December 2013 & 1078 & $15 / 1063$ & 1.39 & $(0.69-2.09)$ & $14 / 1064$ & 1.30 & $(0.62-1.98)$ \\
\hline January 2014 & 1008 & $17 / 991$ & 1.69 & $(0.89-2.49)$ & $14 / 994$ & 1.39 & $(0.67-2.11)$ \\
\hline February 2014 & 826 & $5 / 821$ & 0.60 & $(0.07-1.13)$ & $8 / 818$ & 0.97 & $(0.30-1.64)$ \\
\hline March 2014 & 944 & 11/933 & 1.16 & $(0.48-1.84)$ & $21 / 923$ & 2.22 & $(1.28-3.16)$ \\
\hline April 2014 & 978 & $16 / 962$ & 1.63 & $(0.84-2.42)$ & $14 / 964$ & 1.43 & $(0.69-2.17)$ \\
\hline Total & 10,288 & $120 / 10108$ & 1.163 & $(0.96-1.37)$ & $146 / 10082$ & 1.417 & $(1.24-1.7)$ \\
\hline
\end{tabular}

${ }^{\mathrm{a}} \mathrm{CI}$ represents a 95\% confidence interval.

found that the overall prevalence of HbsAg and HCV was $0.7 \%$ and $0.2 \%$, respectively.

The present study was conducted in the Peshawar district, which is located in the Khyber Pakhtunkhwa province of Pakistan where there are currently serious issues concerning the state of development, economy, socioeconomic status, infrastructure, and available facilities. Due to these limitations, the immunochromatographic technique was used for the detection of HBV and HCV infection in the studied population. As ICT - based detection is inexpensive, rapid, and requires relatively little equipment, it is the only technique available at Molvi Jee Hospital. Several authors have reported that ICT is a better alternative that can be used as a detection method in low income countries $(26,27)$.

In the present study, hepatitis B and C infection among pregnant women was prevalent throughout the year. The application of appropriate screening methods, especially for those of child - bearing age, avoiding the transfusion of unscreened blood and blood products, use of disposable syringes, and education are all needed to improve the health status of pregnant women and their neonates, and appropriate monitoring is needed to control viral infections.

\subsection{Conclusions}

The overall prevalence of HBV was 1.16\%. The highest prevalence (1.69\%) was observed in January 2014. Further, the overall prevalence of HCV infection among pregnant women was $1.42 \%$. The highest prevalence of HCV infection
(2.22\%) was found in March 2014. In the present study, the incidence of HCV infection is higher than that of HBV.

\section{Acknowledgments}

The personal assistance of IA by KFUPM is acknowledged. I would like to thank Dr. Hanifullah for collecting the samples. The valuable suggestions made by Firdous Khanday, Khawar Sohail Siddiqui, and Muhammad Shahid must also be acknowledged. Daniel Nehemiah Oliver is acknowledged for the English editing of the manuscript.

\section{References}

1. Aghemo A, Lampertico P, Colombo M. Assessing long-term treatment efficacy in chronic hepatitis B and C: between evidence and common sense. J Hepatol. 2012;57(6):1326-35. doi: 10.1016/j.jhep.2012.06.025. [PubMed: 22750749].

2. National Survey on Prevalence of Hepatitis B and C in General Population of Pakistan . 2007. Available from: http://www.pmrc.org.pk/ hepatitisbc.htm.

3. Mast EE, Weinbaum CM, Fiore AE, Alter MJ, Bell BP, Finelli L, et al. A comprehensive immunization strategy to eliminate transmission of hepatitis B virus infection in the United States: recommendations of the Advisory Committee on Immunization Practices (ACIP) Part II: immunization of adults. MMWR Recomm Rep. 2006;55(RR-16):1-33. [PubMed: 17159833] quiz CE1-4.

4. Patton H, Tran TT. Management of hepatitis B during pregnancy. Nat Rev Gastroenterol Hepatol. 2014;11(7):402-9. doi: 10.1038/nrgastro.2014.30. [PubMed: 24686270].

5. Lamberth JR, Reddy SC, Pan JJ, Dasher KJ. Chronic hepatitis B infection in pregnancy. World J Hepatol. 2015;7(9):1233-7. doi: 10.4254/wjh.v7.i9.1233. [PubMed: 26019737].

6. Sarkar M, Terrault NA. Ending vertical transmission of hepatitis B: the third trimester intervention. Hepatology. 2014;60(2):448-51. doi: 10.1002/hep.27145. [PubMed: 24668789]. 
7. Shiffman ML. Chronic hepatitis c virus: Advances in treatment, promise for the future. 1st ed. Springer; 2012.

8. Davis GL. Hepatitis C in Schiff's diseases of the liver. Philadelphia: Lippincott Williams and Wilkins; 2007.

9. Bohidar NP. Hepatitis B virus infection in pregnancy. Hep B Annual. 2004;1(1):199-209.

10. Kazmi K, Ghafoor A, Qureshi AW. Mother infant transmission of Hepatitis B in Pakistan. PakJ Med. 2003;42(4):52-6.

11. Qureshi H, Javaid N, Alam SE, Bile KM. The evidence of mother to child transmission of hepatitis B virus infection in Pakistan and the need for hepatitis B immunization policy change. J Pak Med Assoc. 2014;64(4):403-8. [PubMed: 24864633].

12. Roberts EA, Yeung L. Maternal-infant transmission of hepatitis C virus infection. Hepatology. 2002;36(5 Suppl 1):S106-13. doi: 10.1053/jhep.2002.36792. [PubMed: 12407583].

13. World Health Organization . Hepatitis C factsheet Available from: http://www.who.int/mediacentre/factsheets/fs164/en/index.html.

14. Kuncio DE, Newbern EC, Johnson CC, Viner KM. Failure to Test and Identify Perinatally Infected Children Born to Hepatitis C Virus-Infected Women. Clin Infect Dis. 2016;62(8):980-5. doi: 10.1093/cid/ciw026. [PubMed: 26797211].

15. Cottrell EB, Chou R, Wasson N, Rahman B, Guise JM. Reducing risk for mother-to-infant transmission of hepatitis $C$ virus: a systematic review for the U.S. Preventive Services Task Force. Ann Intern Med. 2013;158(2):109-13. doi: 10.7326/0003-4819-158-2-20130115000575. [PubMed: 23437438].

16. Conte D, Fraquelli M, Prati D, Colucci A, Minola E. Prevalence and clinical course of chronic hepatitis $\mathrm{C}$ virus $(\mathrm{HCV})$ infection and rate of HCV vertical transmission in a cohort of 15,250 pregnant women. Hepatology. 2000;31(3):751-5. doi: 10.1002/hep.510310328. [PubMed: 10706568].

17. Gervais A, Bacq Y, Bernuau J, Martinot M, Auperin A, Boyer N, et al. Decrease in serum ALT and increase in serum HCV RNA during pregnancy in women with chronic hepatitis C. J Hepatol. 2000;32(2):293-9. [PubMed: 10707870].

18. Floreani A. Hepatitis C and pregnancy. World J Gastroenterol.
2013;19(40):6714-20. doi: 10.3748/wjg.v19.i40.6714. [PubMed: 24187446].

19. Costa ZB, Machado GC, Avelino MM, Gomes Filho C, Macedo Filho JV, Minuzzi AL, et al. Prevalence and risk factors for Hepatitis C and HIV-1 infections among pregnant women in Central Brazil. BMC Infect Dis. 2009;9:116. doi: 10.1186/1471-2334-9-116. [PubMed: 19635135].

20. Ogunro PS, Adekanle DA, Fadero FF, Ogungbamigbe TO, Oninla SO. Prevalence of anti-hepatitis $C$ virus antibodies in pregnant women and their offspring in a tertiary hospital in Southwestern Nigeria. $J$ Infect Dev Ctries. 2007;1(3):333-6. [PubMed: 19734615].

21. Kumar A, Sharma KA, Gupta RK, Kar P, Chakravarti A. Prevalence \& risk factors for hepatitis $C$ virus among pregnant women. Indian J Med Res. 2007;126(3):211-5. [PubMed: 18037715].

22. Sheikh SM. Hepatitis B and C: value of universal antenatal screening. J Coll Physicians Surg Pak. 2009;19(3):179-82. [PubMed: 19268019].

23. Khattak ST, Ali Marwat M, Khattak I, Khan TM, Naheed T. Comparison of frequency of hepatitis $B$ and hepatitis $C$ in pregnant women in urban and rural area of district Swat. J Ayub Med Coll Abbottabad. 2009;21(2):12-5. [PubMed: 20524459].

24. Murad EA, Babiker SM, Gasim GI, Rayis DA, Adam I. Epidemiology of hepatitis $B$ and hepatitis $C$ virus infections in pregnant women in Sana'a, Yemen. BMC Pregnancy Childbirth. 2013;13:127. doi: 10.1186/14712393-13-127. [PubMed: 23758990].

25. Mohebbi SR, Sanati A, Cheraghipour K, Rostami Nejad M, Shalmani HM, Zali MR. Hepatitis C and hepatitis B virus infection: epidemiology and risk factors in a large cohort of pregnant women in Lorestan, West of Iran. Hepat Mon. 2011;11(9):736-9. doi: 10.5812/kowsar.1735143X.749. [PubMed: 22235217].

26. Hayder I, Ahmed W, Alam SE. Comparison of Different ICT Kits for HBsAg and Anti HCV Using Gold Standard ELISA. Pak J Med Res. 2012;51(3):72-6.

27. Tomar S, Chourey P, Urhekar AD, Kore A. Study of Incidence of Hepatitis B and A Comparative Study to Check the Specificity and Sensitivity of Immunochromatographic Technique CT with Enzyme Linked Immunosorbant Assay (ELISA) for Hepatitis B Infection. 